\title{
Dyslipidaemia in hypertensive obese type 2 diabetic patients in Jamaica
}

Lorenzo Gordon', Dalip Ragoobirsingh², Errol Morrison², Donovan McGrowder ${ }^{3}$, Eric Choo-Kang ${ }^{3}$, E. Martorell ${ }^{4}$

\begin{abstract}
1Department of Medicine, Faculty of Medical Sciences, The University of the West Indies, Kingston, Jamaica

2Department of Basic Medical Sciences (Biochemistry Section), Faculty of Medical Sciences, The University of the West Indies, Kingston, Jamaica

${ }^{3}$ Department of Pathology, Faculty of Medical Sciences, The University of the West Indies, Kingston, Jamaica

${ }^{4}$ Department of Epidemiology, Provincial Centre of Hygiene and Epidemiology of Santiago de Cuba, Cuba
\end{abstract}

Submitted: 15 April 2010

Accepted: 23 June 2010

Arch Med Sci 2010; 6, 5: 701-708

DOI: $10.5114 /$ aoms.2010.17084

Copyright $\odot 2010$ Termedia \& Banach

\begin{abstract}
Introduction: Hypertension and obesity are common problems among diabetic patients accelerating progression of vascular diabetic complications.

Material and methods: A two-stage stratified random sampling design was used, and individuals aged 15 years and over were interviewed. This cross-sectional study evaluated lipid abnormalities of 117 obese type 2 diabetic patients ( 28 males and 89 females), and 56 hypertensive obese type 2 diabetic patients (22 males and 34 females). Total cholesterol (TC), triglycerides (TG), low-density lipoprotein cholesterol (LDL-C), very-low-density lipoprotein cholesterol (VLDL-C) and high-density lipoprotein cholesterol (HDL-C) concentrations were assayed using standard biochemical methods.

Results: Hypertensive obese type 2 diabetic females had significantly higher mean serum concentrations of TC $(p=0.043)$, TG $(p=0.046)$, LDL-C $(p=0.040)$, $\mathrm{TC} / \mathrm{HDL}-\mathrm{C}$ ratio $(p=0.001)$ and LDL-C/HDL-C ratio $(p=0.003)$ compared with hypertensive obese non-diabetic females. Similar results were found in hypertensive obese type 2 diabetic males compared with hypertensive obese non-diabetic males. Hypertensive obese type 2 diabetic females had significantly higher serum TC, TG and TC/HDL-C ratio $(p<0.05)$ than hypertensive obese type 2 diabetic males. Hypertensive obese type 2 diabetic females had significantly higher mean serum concentrations of TG $(p=0.03)$ and TC $(p=0.01)$ than obese type 2 diabetic females. There was a significant association between blood glucose and LDL-C concentrations in type 2 diabetic subjects $(r=0.36 ; p<0.05)$.

Conclusion: Obese hypertensive type 2 diabetic females are exposed more profoundly to risk factors including atherogenic dyslipidaemia compared with males.
\end{abstract}

Key words: dyslipidaemia, obesity, diabetes, lipids, cholesterol, hypertension, Jamaica.

\section{Introduction}

Type 2 diabetes mellitus is one of the most common chronic diseases the world over, and the number of people with diabetes mellitus has risen sharply in recent years [1]. The World Health Organization (WHO) estimated

\section{Corresponding author:} Donovan McGrowder, PhD Department of Basic Medical Sciences Faculty of Medical Sciences The University of the West Indies

Mona Campus, Kingston 7 Jamaica

Phone: +876 9272290

Fax: +876 9773823

E-mail:

dmcgrowd@yahoo.com 
the worldwide prevalence of diabetes mellitus in adults to be around 173 million in 2002 and predicted that there will be at least $350 \mathrm{mln}$ people with type 2 diabetes by 2030 [2]. The largest share of this increase will occur in developing countries, which is expected to show the same current pattern of concentration of cases in the 45-64-year age group [3]. In the Americas, it is estimated that $34 \mathrm{mln}$ persons have diabetes mellitus [4]. The prevalence of diabetes mellitus is high in Jamaica and the Caribbean and many patients have poor metabolic control $[5,6]$. Heart disease is the leading cause of death in persons with diabetes mellitus [7]. Cardiovascular disease in diabetes mellitus is multi-factorial and risk factors include hypertension, dyslipidaemia, insulin resistance and central obesity [8].

Obesity can be described as an imbalance between energy intake and expenditure such that excess energy is stored in fat cells, which enlarge or increase in number. Obesity is defined as a body mass index (BMI) of $>30 \mathrm{~kg} / \mathrm{m}^{2}$, according to $\mathrm{WHO}$ criteria [9]. Obesity and overweight are significant public health problems worldwide, affecting an estimated 1 billion persons and contributing to hypertension, type 2 diabetes mellitus, cardiovascular disease, and death [10-12]. Its prevalence in developed countries, such as the United States, is as high as $26.6 \%$ in men and $32.2 \%$ in women above age 20 years [13].

In the United Kingdom, $12 \%$ of adult females are obese and $24 \%$ overweight, but the rate of increase is faster [14]. The gradient in obesity in women (Nigeria 5\%, urban Cameroon 13\%, Jamaica 18\%, Barbados 30\% and Chicago 36\%) was found to be closely correlated with economic development and with the prevalence of hypertension [15]. Ragoobirsingh et al. reported that Jamaica has a point prevalence of obesity with truncal $36.2 \%$ and gynoid 34.1\%, in the 15 and over age group [16]. In Barbados, data show an increase in obesity prevalence across four surveys, which were done in 1969, 1981, 1987, and 1992 [17]. The Wildey population study of Barbadians aged over 40 showed prevalence in women three times that of men, $30 \%$ vs. $10 \%$ [18].

The Caribbean has demonstrated an increasing prevalence of type 2 diabetes mellitus associated with obesity due to the recent transition to high consumption of energy-dense foods and increasing inactivity [19]. In Jamaica, the adjusted prevalence rates $(95 \% \mathrm{Cl})$ are $9.5 \%(7.0-12.0)$ for men and $15.7 \%$ (13.2-18.3) for women in a population of over $2.6 \mathrm{~m}$ [20]. The characteristic pattern of lipid abnormalities in patients with diabetes mellitus consists of moderate elevation in triglycerides (TG), low high-density lipoprotein cholesterol (HDL-C) concentrations, and an increase in small dense low- density lipoprotein cholesterol (LDL-C) particles [21]. To our knowledge, there has not been any study that has examined lipid abnormalities of obese patients with type 2 diabetes mellitus, and hypertension in Jamaica. This study was designed to investigate the pattern of lipid abnormalities in obese and hypertensive type 2 diabetes mellitus patients in the Jamaican adult population.

\section{Material and methods}

\section{Sample design}

We carried out a transverse study at the University of the West Indies, with the purpose of comparing the lipid profile of obese type 2 diabetic, and hypertensive obese type 2 diabetic subjects with their obese non-diabetic and hypertensive obese non-diabetic counterparts respectively in the Jamaican population. This design was adopted from the Jamaican Labour Force Surveys (LFS) by the Statistical Institute of Jamaica (STATIN) [22], a statutory body in Jamaica with responsibility for census and other official population studies. The design adopted for the LFS was a two-stage stratified sampling design, with the first stage being a selection of areas, Enumeration Districts (ED) of the Population Census, and the second stage being a selection of dwellings. Each dwelling in the sampling universe had an equal probability of being selected for inclusion in the first stage. At the homes visited, only individuals 15 years and over were interviewed and included in the study. A questionnaire was administered by members of the health team to each participant; this included personal, medical and family histories. Informed consent was obtained after the nature of the procedures had been fully explained to the participants. Patients who did not complete the investigations needed for this study, and those on statins or fibrates, were excluded from the study. In addition we excluded persons with disorders that predispose to hyperlipidaemia, such as hypothyroidism and nephrotic syndrome.

At the homes of the participants a fasting blood sample was taken. The fasting blood glucose concentration for each group was determined by using Reflolux S type 1172115 glucometers (Boehringer Mannheim, Germany) [23]. All subjects with a fasting blood glucose of $6.1 \mathrm{mmol} / \mathrm{l}$ or above were asked to attend a nearby health facility, the day after an overnight fast (12-14 hours), without consuming anything that morning. At the health facility, an abbreviated glucose tolerance test (GTT) was conducted on each subject. Fasting blood glucose (FBG) was measured on arrival at the clinic, followed by a drink containing $75 \mathrm{~g}$ of glucose. Two hours later a second blood glucose measurement was taken. A fasting blood glucose of $6.7 \mathrm{mmol} / \mathrm{l}$ 
or above, or a two-hour postprandial blood glucose of $11.1 \mathrm{mmol} / \mathrm{l}$ or above, was viewed as indicative of diabetes mellitus [24]. The plasma glucose concentration of the fasting and postprandial blood samples were determined based on the glucoseoxidase method using a multi-channel Abbott Spectrum Autoanalyzer (Abbott Laboratories, Abbott Park, USA). Glucose oxidase catalyses the oxidation of glucose to gluconic acid. The generation of hydrogen peroxide is indirectly measured by oxidation of o-dianisidine in the presence of peroxidase [25]. Obesity was defined as a body mass index (BMI) of $>30 \mathrm{~kg} / \mathrm{m}^{2}$, according to WHO criteria [9]. Blood pressure (systolic and diastolic) measurements were taken using a mercury sphygmomanometer with standard technique by a trained health professional [26]. Patients were allowed to rest for $30 \mathrm{~min}$. All measurements were made in the morning between 9:00 and 10:00 a.m. The mean of two blood pressures was recorded while the patients were seated. Hypertension was defined as a systolic blood pressure reading greater than $140 \mathrm{mmHg}$ and/or a diastolic reading greater than $90 \mathrm{mmHg}$.

\section{Biochemical analysis}

Biochemical assays on the serum were performed with a multi-channel Abbott Spectrum Autoanalyzer (Abbott Laboratories, Abbott Park, USA). Parameters that were determined include: total cholesterol (TC), TG, HDL-C, LDL-C and very-low-density lipoprotein cholesterol (VLDL-C). Total cholesterol was determined by an enzymatic method. The cholesterol esters are hydrolyzed to free cholesterol by cholesterol esterase. The free cholesterol is then oxidized by cholesterol oxidase to cholesten-3-one with the simultaneous production of hydrogen peroxide. The hydrogen peroxide produced couples with 4-aminoantipyrine and phenol, in the presence of peroxidase, to yield a chromogen with maximum absorbance at $505 \mathrm{~nm}$ [27]. HDL-C was measured by an enzymatic method on the supernatant obtained after selective precipitation of apolipoprotein B-containing lipoproteins with phosphotungstic acid in the presence of magnesium ions and centrifugation [28]. Triglyceride determination was carried out by an analytical method based on the sequence of reactions described by Fossati et al. [29]. In this direct colorimetric procedure, serum triglycerides are hydrolyzed by lipase, and the released glycerol is assayed in a reaction catalyzed by glycerol kinase and L-alpha-glycerol-phosphate oxidase in a system that generates hydrogen peroxide. The hydrogen peroxide is monitored in the presence of horseradish peroxidase with 3,5-dichloro-2hydroxybenzenesulfonic acid/4-aminophenazone as the chromogenic system. The absorbance of this chromogen system is measured at $510 \mathrm{~nm}$ [29]. The methods adopted by the automated instrument for the determination of the above parameters are according to the instructions of the manufacturer, Abbott Laboratories (Abbott Diagnostics, Illinois, USA). Serum LDL-C was calculated according to computational procedures of Friedewald et al. [30] $(\mathrm{LDL}=\mathrm{TC}-\mathrm{HDL}-\mathrm{C}-\mathrm{TG} / 2.2[\mathrm{mmol} / \mathrm{l}])$. Calculation of VLDL-C was $1 / 5$ of TG concentration.

\section{Statistical analysis}

Values for the continuous variables are expressed as mean \pm SD. Comparisons of males and females with obesity and type 2 diabetes mellitus, and those with hypertension, obesity and type 2 diabetes mellitus, against their obese non-diabetic and hypertensive obese non-diabetic counterparts, respectively, were performed using unpaired Student's t test for independent samples; a level of $p<0.05$ was considered as statistically significant. Independent observations were assumed using Fisher's exact test and 0.05 was taken to be the cut-off for acceptability of significance levels. The study parameters showed non-Gaussian distribution and statistical significance was assessed by the Mann-Whitney U test [31]. Statistics were computed using SPSS 11.5 (SPSS Inc., Chicago, Illinois, United States).

\section{Results}

In the island-wide study, 2108 subjects were studied, 402 type 2 diabetic (19.1\%) and 1706 nondiabetic subjects (80.9\%). There were 117 obese type 2 diabetics and 56 obese hypertensive type 2 diabetics. Of the non-diabetic subjects, 1179 were non-diabetic without other diseases. There were 156 obese non-diabetics and 117 hypertensive obese non-diabetics (Table I).

Obese type 2 diabetic males had significantly higher serum concentrations of TG than their obese non-diabetic counterparts ( $p=0.039$; Table II).

Table I. Distribution of type 2 diabetes mellitus subjects according to gender

\begin{tabular}{|lccc|}
\hline Characteristic & \multicolumn{3}{c|}{ Gender } \\
\cline { 2 - 4 } & Male & Female & Total \\
& $N(\%)$ & $N(\%)$ & $N$ \\
\hline Obese type 2 diabetics & $28(24.0)$ & $89(76.0)$ & 117 \\
\hline Obese non-diabetics & $59(37.7)$ & $97(62.3)$ & 156 \\
\hline $\begin{array}{l}\text { Hypertensive obese } \\
\text { type 2 diabetics }\end{array}$ & $22(39.6)$ & $34(60.4)$ & 56 \\
\hline $\begin{array}{l}\text { Hypertensive obese } \\
\text { non-diabetics }\end{array}$ & $41(35.2)$ & $76(64.8)$ & 117 \\
\hline Total & 150 & 296 & 446 \\
\hline
\end{tabular}


Similarly, obese type 2 diabetic females had significantly higher serum concentrations of TG than obese non-diabetic females ( $p=0.019$; Table III).

Hypertensive obese type 2 diabetic males had significantly higher mean serum concentrations of TC $(p=0.031)$, TG $(p=0.007)$, LDL-C $(p=0.044)$ and $\mathrm{TC} / \mathrm{HDL}-\mathrm{C}$ ratio $(p=0.004)$ compared with hypertensive obese non-diabetic males (Table IV). Hypertensive obese type 2 diabetic females had

Table II. Comparison of the lipid profile between obese type 2 diabetic and obese non-diabetic males

\begin{tabular}{|lccc|}
\hline $\begin{array}{l}\text { Lipid profile } \\
\text { [mmol/I] }\end{array}$ & $\begin{array}{c}\text { Obese type } 2 \\
\text { diabetic } \\
\text { Mean } \pm \text { SD }\end{array}$ & $\begin{array}{c}\text { Obese } \\
\text { non-diabetic } \\
\text { Mean } \pm \text { SD }\end{array}$ & $p$ \\
\hline Triglyceride & $1.65 \pm 0.61$ & $1.45 \pm 0.79$ & 0.039 \\
\hline LDL-C & $3.23 \pm 0.96$ & $2.78 \pm 1.00$ & 0.161 \\
\hline VLDL-C & $0.39 \pm 0.04$ & $0.38 \pm 0.19$ & 0.984 \\
\hline HDL-C & $0.90 \pm 0.20$ & $1.04 \pm 0.47$ & 0.361 \\
\hline Total cholesterol & $5.44 \pm 1.48$ & $5.19 \pm 1.02$ & 0.159 \\
\hline LDL/HDL ratio & $3.84 \pm 0.98$ & $3.03 \pm 0.67$ & 0.100 \\
\hline TC/HDL ratio & $6.83 \pm 1.73$ & $5.63 \pm 0.60$ & 0.089 \\
\hline
\end{tabular}

Table III. Comparison of the lipid profile between obese type 2 diabetic and obese non-diabetic females

\begin{tabular}{|lccc|}
\hline $\begin{array}{l}\text { Lipid profile } \\
\text { [mmol/l] }\end{array}$ & $\begin{array}{c}\text { Obese type } 2 \\
\text { diabetic } \\
\text { Mean } \pm \text { SD }\end{array}$ & $\begin{array}{c}\text { Obese } \\
\text { non-diabetic } \\
\text { Mean } \pm \text { SD }\end{array}$ & $p$ \\
\hline Triglyceride & $1.67 \pm 0.89$ & $1.51 \pm 1.20$ & 0.019 \\
\hline LDL-C & $3.20 \pm 1.21$ & $3.10 \pm 1.18$ & 0.650 \\
\hline VLDL-C & $0.43 \pm 0.30$ & $0.39 \pm 0.09$ & 0.699 \\
\hline HDL-C & $1.07 \pm 0.65$ & $1.29 \pm 0.36$ & 0.216 \\
\hline Total cholesterol & $5.80 \pm 1.54$ & $5.68 \pm 1.68$ & 0.721 \\
\hline LDL/HDL ratio & $4.87 \pm 2.84$ & $3.14 \pm 1.53$ & 0.060 \\
\hline TC/HDL ratio & $7.08 \pm 4.07$ & $5.75 \pm 2.40$ & 0.099 \\
\hline
\end{tabular}

Table IV. Comparison of the lipid profile between hypertensive obese type 2 diabetic and hypertensive obese non-diabetic males

\begin{tabular}{|lccc|}
\hline $\begin{array}{l}\text { Lipid profile } \\
\text { [mmol/l] }\end{array}$ & $\begin{array}{c}\text { Hypertensive } \\
\text { obese } \\
\text { type 2 diabetic } \\
\text { Mean } \pm \text { SD }\end{array}$ & $\begin{array}{c}\text { Hypertensive } \\
\text { obese } \\
\text { non-diabetic } \\
\text { Mean } \pm \text { SD }\end{array}$ & $p$ \\
\hline Triglyceride & $1.96 \pm 1.14$ & $1.53 \pm 1.34$ & 0.007 \\
\hline LDL-C & $3.29 \pm 1.21$ & $2.99 \pm 1.18$ & 0.044 \\
\hline VLDL-C & $0.43 \pm 0.90$ & $0.35 \pm 0.07$ & 0.538 \\
\hline HDL-C & $1.07 \pm 0.43$ & $1.08 \pm 0.43$ & 0.835 \\
\hline Total cholesterol & $5.37 \pm 1.61$ & $4.67 \pm 1.38$ & 0.031 \\
\hline LDL/HDL ratio & $3.29 \pm 1.51$ & $3.10 \pm 1.15$ & 0.581 \\
\hline TC/HDL ratio & $6.98 \pm 2.14$ & $5.70 \pm 0.20$ & 0.004 \\
\hline
\end{tabular}

significantly higher mean serum concentrations of TC $(p=0.043)$, TG $(p=0.046)$, LDL-C $(p=0.04)$, $\mathrm{TC} / \mathrm{HDL}-\mathrm{C}$ ratio $(p=0.001)$ and $\mathrm{LDL}-\mathrm{C} / \mathrm{HDL}-\mathrm{C}$ ratio $(p=0.003)$ compared with hypertensive obese nondiabetic females (Table $\mathrm{V}$ ).

Hypertensive obese type 2 diabetic females had significantly higher serum concentrations of TC, TG and TC/HDL-C $(p<0.05)$ than hypertensive obese type 2 diabetic males. Hypertensive obese type 2 diabetic females had significantly higher mean serum concentrations of TG $(p=0.03)$ and TC $(p=0.01)$ than obese type 2 diabetic females.

There was a significant association between blood glucose and LDL-C concentrations in type 2 diabetic subjects $(r=0.36 ; 95 \%$ confidence limits $=0.23<r<0.47 ; p<0.05)$. In addition, there was a significant correlation between blood glucose and TC concentrations in type 2 diabetic subjects $(r=0.33 ; 95 \%$ confidence limits $=0.26<r<0.49$; $p<0.05)$.

\section{Discussion}

Diabetes mellitus is often associated with cardiovascular morbidity and this may partly be explained by the abnormal lipid profile which is sometimes a feature of diabetes. We studied the pattern of lipid abnormalities in a population of type 2 diabetic, obese and hypertensive subjects drawn from the 14 parishes in Jamaica. The magnitude of the detected abnormalities showed that TG was the parameter that was most affected as it showed the most significant mean difference between the values of those patients in the obese type 2 diabetic group, and their counterparts in the obese nondiabetic group for both males and females, thus implying a higher cardio-metabolic risk. The hypertriglyceridaemia associated with obesity and insulin resistance in type 2 diabetes was thought to be secondary to the effects of elevated plasma insulin levels causing increased hepatic fatty acid

Table V. Comparison of the lipid profile between hypertensive obese type 2 diabetic and hypertensive obese non-diabetic females

\begin{tabular}{|lccc|}
\hline $\begin{array}{l}\text { Lipid profile } \\
\text { [mmol/l] }\end{array}$ & $\begin{array}{c}\text { Hypertensive } \\
\text { obese } \\
\text { type } 2 \text { diabetic } \\
\text { Mean } \pm \text { SD }\end{array}$ & $\begin{array}{c}\text { Hypertensive } \\
\text { obese } \\
\text { non-diabetic } \\
\text { Mean } \pm \text { SD }\end{array}$ & $p$ \\
\hline Triglyceride & $2.00 \pm 0.34$ & $1.76 \pm 0.43$ & 0.046 \\
\hline LDL-C & $3.42 \pm 1.18$ & $2.87 \pm 0.92$ & 0.041 \\
\hline VLDL-C & $0.50 \pm 0.00$ & $0.40 \pm 0.29$ & 0.747 \\
\hline HDL-C & $1.02 \pm 0.37$ & $1.50 \pm 0.23$ & 0.495 \\
\hline Total cholesterol & $8.70 \pm 1.30$ & $6.12 \pm 1.38$ & 0.043 \\
\hline LDL/HDL ratio & $4.01 \pm 1.68$ & $3.56 \pm 1.25$ & 0.003 \\
\hline TC/HDL ratio & $8.16 \pm 2.50$ & $5.90 \pm 1.62$ & 0.001 \\
\hline
\end{tabular}


esterification, which forms triglyceride [32]. It has been proposed that insulin resistance leads to elevated TG levels in obesity through decreased adipose tissue lipoprotein lipase activity [33].

The major risk factors in type 2 diabetes are glycaemic status, dyslipidaemia and hypertension. Type 2 diabetic patients have a high frequency of atherogenic dyslipidaemia especially for TC and LDL-C [34]. The parameters TC, TG, LDL-C and $\mathrm{TC} / \mathrm{HDL}-\mathrm{C}$ ratio showed significant mean differences between values in the hypertensive obese diabetic subjects compared with the hypertensive obese non-diabetics for both males and females. This indicates that the presence of type 2 diabetes is responsible for the more atherogenic pattern. The finding of elevated LDL-C in hypertensive obese type 2 diabetic subjects is of crucial importance as it represents the first alarming risk for cardiovascular diseases. According to the National Cholesterol Education Program (NCEP) guidelines LDL-C is the main target of cardiovascular disease prevention [35]. Elevated cholesterol though not usually regarded as highly predictive of cardiovascular disease was noted in a significant number of the participants in this study, particularly females. The significance of screening for total cholesterol in this study lies in the fact that it could serve as a valuable screening measure for dyslipidaemia.

The significant elevation of TC/HDL-C ratio in hypertensive obese diabetic males and females is a key finding. A study by Kinosian et al. showed that the TC/HDL-C ratio is a better predictor of atherosclerosis and cardiovascular disease than any other single lipid [36]. Individuals with increased TC/HDL-C ratio were shown to exhibit resistance to insulin-stimulated disposal and to have higher blood pressure, increased TG concentration and hyperinsulinaemia. Each of these factors being a part of the metabolic syndrome is an independent risk factor for cardiovascular disease [37]. The hypertensive obese diabetic females in this study had the highest TC/HDL-C ratio and mean TG concentration, and are therefore at the greatest risk for cardiovascular disease.

Several large epidemiological and clinical studies have found the LDL-C/HDL-C ratio to be an excellent predictor of coronary heart disease risk and an excellent monitor for the effectiveness of lipidlowering therapies [38-41]. Therefore it was important to evaluate the LDL-C/HDL-C ratio of the participants in this study. The increased LDL-C/HDL-C ratio observed in the hypertensive obese type 2 diabetic females and males in this study indicates an increased risk of developing coronary heart disease [42]. In the PROSPER trial, a retrospective analysis of 6,000 patients, the ratio of $\mathrm{LDL}-\mathrm{C} / \mathrm{HDL}-\mathrm{C}$ was the most powerful measure of cardiovascular disease risk in elderly people [43]. The researchers concluded that changes in LDL-C/HDL-C ratio as a result of statin treatment appeared to account for the beneficial effects of therapy and suggested that statin therapy could usefully be targeted to those with an LDL-C/HDL-C ratio > 3.3 [43]. It is important to note that while the mean $\mathrm{LDL}-\mathrm{C} / \mathrm{HDL}-\mathrm{C}$ ratio of the hypertensive obese type 2 diabetic males in this study was 3.29, the value for the females was 4.01. This indicates that the females are at greater risk of developing cardiovascular disease and could benefit more from statin therapy.

Hypertension is one of the most important treatable causes of morbidity and mortality and accounts for a large proportion of cardiovascular diseases in the elderly in Jamaica [44]. The age-and sex-adjusted prevalence in Jamaica is $24 \%$ [45], with somewhat higher levels in women than in men. In a paper published from the data in this study, Ragoobirsingh et al. reported that Jamaica has a point prevalence of hypertension of $30.8 \%$ in the 15 -and-over age group. The main risk factors for hypertension are being female, advancing age, obesity, having diabetes and having a family history of hypertension [46]. We report a higher significant mean difference between TC and TG in hypertensive obese type 2 diabetic females compared with obese type 2 diabetic females. The presence of hypertension may be contributory to the greater prevalence of dyslipidaemia observed in the former group. In explaining this scenario, insulin resistance or compensatory hyperinsulinaemia has been associated with hypertension and dyslipidaemia in cross-sectional studies [47, 48]. Insulin resistance often leads to increased intracellular hydrolysis of triglycerides and release of fatty acids into the circulation. The resultant inability of fat cells to store triglyceride is the initial step in the development of dyslipidaemia. Other plausible explanations for the contributory effect of hypertension to abnormal lipid profiles in diabetes mellitus include use of antihypertensive agents [49]. Beta blockers and diuretics, especially thiazide diuretics, have been found to negatively affect the lipid profile and glucose tolerance. Thiazides in high dosage and loop diuretics can increase serum LDL-C, TG, TC/HDL-C ratio and often TC [50]. These blood pressure lowering agents are commonly used for the purpose of blood pressure control in patients with diabetes and hypertension.

Obesity, and especially intra-abdominal fat, is strongly associated with insulin resistance, glucose intolerance, and diabetes mellitus, and is a growing problem in Jamaica [51]. Contributory to this is the westernization of traditional Jamaican diets, with fruits, vegetables, and whole grains being replaced by readily-accessible fast foods, which are high in saturated fat, sugars and refined carbohydrates. In 
another paper published from the data in this study, Ragoobirsingh et al. reported that Jamaica has a point prevalence of obesity, truncal $36.2 \%$ and gynoid $34.1 \%$, in the 15 -and-over age group. Both were affected by increasing age, being female, level of education attained and smoking status [52]. Gender was found to be a possible determinant of the pattern of lipid profile levels in participants in the study. In particular, obesity was more prevalent among females [52]. We report a higher significant mean difference between TC, TG and TC/HDL-C ratio in hypertensive obese type 2 diabetic females compared with hypertensive obese type 2 diabetic males, indicating a higher prevalence of lipid abnormalities and greater atherogenic risk. King et al. reported that the risk of coronary heart disease in diabetic females is related to age, reproductive and hormonal status as well as HDL-C, TC and TG [53].

A high dietary energy and fat intake is likely to be a major contributing factor to the high prevalence of obesity and evidence of dyslipidaemia in the Jamaican population, particularly those living in urban areas. There is the westernization of traditional Jamaican diets, with fruits, vegetables, and whole grains being replaced by readily-accessible fast foods, which are high in saturated fat, sugars and refined carbohydrates. However, a high dietary fat intake alone cannot account for the extent of the problem. In Jamaica, there is a cultural acceptance of obesity, especially in women [54]. Fewer than half of the subjects recognized poor diet and/or overweight as contributing to their diabetes. Firmly rooted social and economic factors actively encourage over-eating and sedentary behaviour and discourage alterations in these patterns [55]. Physical inactivity among the participants may be a significant contributory factor of their obesity, as a national study recently conducted in Jamaica revealed that only $21.6 \%$ of the sample participated in planned exercise [56]. Furthermore, indiscriminate eating patterns could have a direct and unfavourable influence on weight management and glycaemic control.

Despite the importance of these findings of dyslipidaemia and increased atherogenic risk in hypertensive obese type 2 diabetics, and obese type 2 diabetics in a representative sample of the Jamaican population, there are some limitations in the study. We did not acquire any information about the hormonal status of our women subjects. Thus, we do not know whether these women went through earlier menopause and whether this was related to redistribution of fat. Physical activity was not considered and the amount of alcohol and tobacco use was not quantified in our study. These 3 lifestyle factors have been reported to be quantitatively correlated with plasma lipid levels $[57,58]$. Also, data on the socioeconomic status of the patients were not available, to check for its influence on the dyslipidaemic state of the participants. The study could have been strengthened by the measurement of anthropometric variables such as higher waist circumference, BMI and waist-to-hip ratio, as these have been found to be significantly associated with dyslipidaemia in males and females.

In conclusions, obesity is a significant problem in the Caribbean countries, including Jamaica, and it is associated with a high prevalence of hypertension, particularly in women. Our study provided evidence for the presence of significant dyslipidaemia in obese type 2 diabetes mellitus and hypertensive obese type 2 diabetes mellitus patients. Future research should focus on intervention strategies aimed at reducing obesity and its morbid sequelae. These strategies should be culturally specific, with a particular focus on children and women, and should include dietary and behavioural aspects, weight reduction, increased physical activity, improved glycaemic control, and increased HDL cholesterol levels, along with reduced LDL cholesterol.

\section{References}

1. Wild S, Roglic G, Green A, Sicree R, King H. WHO-global prevention of diabetes: estimates for the year 2000 and projections for 2030. Diabetes Care 2004; 27: 1047-53.

2. Caribbean Health Research Council/PAHO. Managing diabetes in primary Care in the Caribbean. CHRC; St. Augustine, Trinidad and Tobago, 2006. http://www.chrccaribbean.org/files/Guidelines/Diabetes Guidelines.pdf

3. Nayaran KM, Gregg EW, Fagot-Campagna A, Engelgau MM, Vinicor F. Diabetes: a common, growing, serious, costly and potentially preventable public health problem. Diabetes Res Clin Pract 2000; 50 (Suppl. 2): S77-84.

4. King $\mathrm{H}$, Aubert RE, Herman WH. Global burden of diabetes, 1995-2005: prevalence, numerical estimates, and projections. Diabetes Care 1998; 21: 1414-31.

5. Wilks R, Sargeant L, Gulliford M, Reid M, Forrester T. Management of diabetes mellitus in three settings in Jamaica. Pan Am J Public Health 2001; 9: 65-71.

6. Ezenwaka CE, Offiah NV. Classical cardiovascular risk factors in Trinidadian patients with type 2 diabetes mellitus are not influenced by the level of plasma glycaemia. West Indian Med J 2001; 50: 288-93.

7. American Diabetes Association: Diabetes 1996 Vital Statistics. Alexandria, VA, American Diabetes Association, 1996.

8. Liebl A, Mata M, Eschwege E. Evaluation of risk factors for development of complications in type 2 diabetes in Europe. Diabetologia 2002; 45: S23-8.

9. World Health Organization. Physical Status: The Use and Interpretation of Anthropometry. Technical Report Series 854. 1-1-9950. Geneva, Switzerland, World Health Organization, 1995.

10. Froguel P, Boutin P. Genetics of pathways regulating body weight in the development of obesity in humans. Exp Biol Med 2001; 226: 991-6.

11. Boutin P, Froguel P. Genetics of human obesity. Best Pract Res Clin Endocrinol Metab 2001; 15: 391-404.

12. Peeters A, Barendregt JJ, Willekens F, Mackenbach JP, Al Mamun A, Bonneux L. Obesity in adulthood and its 
consequences for life expectancy: a life table analysis Ann Intern Med 2003; 138: 24-32.

13. World Health Organization. United States of America: Report : BCP 2005 [On line]. Available: http://www.who.int/ ncd surveillance/infobase/web/InfoBaseCommon/

14. Seidell JC, Flegal KM. Assessing obesity: classification and epidemiology. Br Med Bull 1997; 53: 238-52.

15. Fraser HS. Obesity: diagnosis and prescription for action in the English-speaking Caribbean. Rev Panam Salud Publica 2003; 13: 336-40.

16. Ragoobirsingh D, Lewis-Fuller E, Morrison EY. The Jamaican Diabetes Survey. A protocol for the Caribbean. Diabetes Care 1995; 18: 1277-29.

17. Fraser HS, Forrester T, Wilks R. The obesity epidemic of the Caribbean. West Ind Med J 1996; 45: 1-2.

18. Foster C, Rotimi C, Fraser H, et al. Hypertension, diabetes and obesity in Barbados: findings from a recent population-based study. Ethn Dis 1993; 3: 404-12.

19. Xuereb G, Chambers C, Trotter P, Forrester C, Henry F. Obesity prevention in the Caribbean: The stages of change model results from the qualitative phase of the study. Cajanus 2003; 36: 21-7.

20. Barcelo A, Rajpathak S. Incidence and prevalence of diabetes mellitus in the Americas. Rev Panam Salud Publica 2001; 10: 300-8.

21. Chahil TJ, Ginsberg HN. Diabetic dyslipidemia. Endocrino Metab Clin North Am 2006; 35: 491-510.

22. The Statistical Institute of Jamaica. Demographic statistics. Kingston, Jamaica 1993.

23. Kalk WJ, Constable J, Osler C, Rowe P. Evaluation of a new blood glucose meter and comparison with visually interpreted strips. S Afr Med J 1985; 67: 407-9.

24. Diabetes Mellitus: Report of a WHO Study Group (Review). World Health Organ Tech Rep Ser 1985; 727: 1-113.

25. Huggert A, St G, Nixon DA. Use of glucose oxidase, peroxidase, and o-dianisidine in determination of blood and urinary glucose. Lancet 1957; 314: 368-70.

26. Perloff D, Grim C, Flack J, et al. Human blood pressure determination by sphygmanometry. Circulation 1993. 88:460.

27. Allain C, Poon L, Chan S, Richmond W, Fu P. Enzymatic determination of total serum cholesterol. Clin Chem 1974; 20: 470 .

28. Burstein M, Scholnick HR, Morfin R. Rapid method for isolation of lipoproteins from human serum by precipitation with polyanions. J Lipid Res 1970; 11: 583-95.

29. Fossati P, Prencipe L. Serum triglycerides determined colorimetrically with an enzyme that produces hydrogen peroxide. Clinical Chemistry 1982; 28: 2077-80.

30. Friedewald W, Levy RI, Fredrickson DS. Estimation of the concentration of low density lipoprotein cholesterol in plasma, without use of the preparative ultracentrifuge. Clin Chem 1972; 18: 499-502.

31. Feinstein A. Clinical epidemiology, the architecture of clinical research. $1^{\text {st }}$ edition. WB Saunders Co; 1985, 690-3.

32. Soler-Argilaga C, Russell RL, Werner HV, Heimberg $M$. A possible role of calcium in the action of glucagon, CAMP and dibutyryl CAMP on the metabolism of free fatty acids by rat hepatocytes. Biochem Biophys Res Commun 1978; 85: 249-56.

33. Grundy SM, Mok HYI, Zech L, Steinberg D, Berman M. Transport of very low density lipoprotein triglycerides in varying degrees of obesity and hypertriglyceridemia. J Clin Invest 1979; 63: 1274-83.

34. King H, Balkau B, Zimmet $P$, et al. Diabetic retinopathy in Nauruans. Am J Epidemiol 1983; 117: 659-67.

35. National Cholesterol Education Program (NCEP) Expert Panel on Detection, Evaluation, and treatment of High
Blood Cholesterol in Adults (Adult Treatment Panel III). Third Report of the National Cholesterol Education Program (NCEP) Expert Panel on Detection, Evaluation, and Treatment of High Blood Cholesterol in Adults (Adult Treatment Panel III) final report. Circulation 2002; 106: 3143-421.

36. Kinosian B, Glick H, Garland G. Cholesterol and coronary heart disease: predicting risks by levels and ratios. Ann Intern Med 1994; 121: 641-7.

37. Loock ME, van Staden DA. Ischemic heart disease in urban blacks. S Afr Med J 1983; 63: 635-6.

38. Manninen V, Tenkanen L, Koskinen P, et al. Joint effects of serum triglyceride and LDL cholesterol and HDL cholesterol concentrations on coronary heart disease risk in the Helsinki Heart Study. Implications for treatment. Circulation 1992; 85: 37-45.

39. Kannel WB. Risk stratification of dyslipidemia: insights from the Framingham Study. Curr Med Chem Cardiovasc Hematol Agents 2005; 3: 187-93.

40. Cullen P, Schulte H, Assmann G. The Munster Heart Study (PROCAM) Total Mortality in Middle-Aged Men is increased at low total and LDL cholesterol concentrations in smokers but not in nonsmokers. Circulation 1997; 96: 2128-36.

41. Stampfer MJ, Sacks FM, Salvini S, Willett WC, Hennekens $\mathrm{CH}$. A prospective study of cholesterol apolipoproteins and the risk of myocardial infarction. N Engl J Med 1991; 325: 373-81.

42. Executive Executive Summary of The Third Report of The National Cholesterol Education Program (NCEP). Expert Panel on Detection, Evaluation, And Treatment of High Blood Cholesterol In Adults (Adult Treatment Panel III). JAMA 2001; 285: 2486-97.

43. Packard CJ, Ford I, Robertson M, et al. PROSPER Study Group: Plasma lipoproteins and apolipoproteins as predictors of cardiovascular risk and treatment benefit in the PROspective Study of Pravastatin in the Elderly at Risk (PROSPER). Circulation 2005; 112: 3058-65.

44. Sargeant L, Boyne M, Bennett F, Forrester T, Cooper R, Wilks R. Impaired glucose regulation in adults in Jamaica: Who should have the oral glucose tolerance test? Rev Panam Salud Publica 2004; 16: 35-42.

45. Cooper R, Rotimi C, Ataman S, et al. The prevalence of hypertension in seven populations of West African origin. Am J Public Health 1997; 7: 160-8.

46. Ragoobirsingh D, McGrowder D, Morrison EY, Johnson P, Lewis-Fuller E, Fray J. The Jamaican hypertension prevalence study. J Natl Med Assoc 2002; 94: 561-5.

47. Ferrannini E, Buzzigoli G, Bonadonna R, et al. Insulin resistance in essential hypertension. N Engl J Med 1987; 317: 350-7.

48. Salonen JT, Lakka TA, Lakka AM, Valkonen VP, Everson SA, Kaplan GA. Hyperinsulinaemia is associated with the incidence of hypertension and dyslipidaemia in middle aged men. Diabetes 1998; 47: 270-5.

49. Ferrari P, Rosner J, Weidmzn P. Antihypertensive agents serum lipoproteins and glucose metabolism. Am J Cardiology 1991; 57: 26B-35B.

50. Weidmann P, de Courten M, Ferrari P. Effect of diuretics on the plasma lipid profile. Eur Heart J 1992; 22 (Suppl. G): 61-7.

51. Durazo-Arvizu RA, Luke A, Cooper RS, et al. Rapid increases in obesity in Jamaica, compared to Nigeria and the United States. BMC Public Health 2008; 8: 133

52. Ragoobirsingh D, Morrison EY, Johnson P, Lewis-Fuller E. Obesity in the Caribbean: the Jamaican experience. Diabetes Obes Metab 2004; 6: 23-7. 
53. King KB, Mosca L. Prevention of heart disease in women: recommendations for management of risk factors. Prog Cardiovasc Nurs 2000; 15: 36-42.

54. Chutkan ME, Meeks-Gardner J, Wilks R. Concepts of obesity among outpatients of a Jamaican hospital. Cajanus 2001; 34: 127-34.

55. Henry F. Diet, performance and healthy lifestyle. Cajanus 2002; 35: 210-3.

56. Caribbean Food and Nutritional Institute. Physical activity status among urban and rural Jamaicans. 1998.

57. Devroey D, Swaef ND, Coigniez P, Vandevoorde J, Kartonuian J, Betz W. Correlations between lipid levels and age, gender, glycemia, obesity, diabetes and smoking. Endocr Res 2004; 30: 83-93.

58. Lai SW, Ng KC. Which anthropometric indices best predict metabolic disorders in Taiwan? South Med J 2004; 97 . 578-82. 